\title{
Assisted and unassisted suicide in men and women: Iongitudinal study of the Swiss population
}

\author{
Nicole Steck, Matthias Egger and Marcel Zwahlen for the Swiss National Cohort
}

\section{Background}

In Switzerland assisted suicide is legal if no self-interest is involved.

\section{Aims \\ To compare the strength and direction of associations with sociodemographic factors between assisted and unassisted suicides. \\ Method \\ We calculated rates and used Cox and logistic regression models in a longitudinal study of the Swiss population.}

\section{Results}

Analyses were based on 5004403 people, 1301 assisted and 5708 unassisted suicides from 2003 to 2008. The rate of unassisted suicides was higher in men than in women, rates of assisted suicides were similar in men and women.
Higher education was positively associated with assisted suicide, but negatively with unassisted. Living alone, having no children and no religious affiliation were associated with higher rates of both.

\section{Conclusions}

Some situations that indicate greater vulnerability such as living alone were associated with both assisted and unassisted suicide. Among the terminally ill, women were more likely to choose assisted suicide, whereas men died more often by unassisted suicide.

\section{Declaration of interest}

None.

\section{Copyright and usage}

(c) The Royal College of Psychiatrists 2016.
Suicide is an important public health issue worldwide. ${ }^{1}$ In Switzerland, suicide is an important cause of death in all age groups and the most frequent one in people aged 15-40 years. ${ }^{2}$ With an age-standardised rate of 9.2 per 100000 population, suicide is more common in Switzerland than in other European countries, for example Italy (5.0 per 100000$)$ or the UK $(6.2$ per $100000) .{ }^{1}$ Mental disorders are the main risk factor for suicides ${ }^{3}$ but sociodemographic factors such as an affiliation or no affiliation to a religion, level of educational attainment and marital status are also associated with risk of suicide. ${ }^{4-6}$

Switzerland is one of only a few countries and states where assisted suicide is legal. ${ }^{7}$ Whereas euthanasia is prohibited, assistance in suicide is allowed if no self-interest is involved. In 1918, at the time the law was proposed, the lawmakers were concerned with suicides motivated by honour and romance and did not intend to regulate assisted suicide from a medical perspective. Today, suicides are assisted by volunteers working for right-to-die associations established in recent decades. The role of physicians is restricted to assessing the decisional capacity of the person requesting assistance, and to prescribing the lethal drug. Although most individuals choosing assisted suicide are terminally ill or suffer unbearably, assisting suicides is also legal in the healthy. ${ }^{7-11}$

We previously analysed the Swiss National Cohort (SNC), a longitudinal cohort study of the entire Swiss population, to examine the socioeconomic and demographic factors associated with assisted suicide. ${ }^{12}$ We found that assisted suicide was more likely in women than in men, those living alone compared with those living with others and in those with no religious affiliation compared with Protestants or Catholics. Social isolation, loneliness and advanced disease are also well-known risk factors for unassisted suicide. ${ }^{5,6}$ No studies have compared the importance of these risk factors in assisted and unassisted suicide to date. If and how physician-assisted suicide and ordinary unassisted suicide differ in motivation is part of the ongoing debates about assisted dying in Western societies. ${ }^{13,14}$ In the present analysis we compared the association of socioeconomic and demographic factors with assisted and unassisted suicides in men and women. We were interested in the strength of associations and examined to what extent men and women with terminal disease or unbearable suffering differ in their choice of assisted or unassisted suicide.

\section{Method}

\section{The SNC}

The SNC is a longitudinal study of mortality in Switzerland. ${ }^{15,16}$ Briefly, the records of the 1990 and 2000 censuses were linked to death or emigration records. Deterministic and probabilistic record linkage was based on gender, date of birth and place of residence. The present analysis is based on the population registered in the 2000 census, for which the Federal Statistical Office (FOS) estimated a coverage of $98.6 \% .{ }^{17}$ We excluded people younger than 25 years or older than 94 years at the 2000 census because linkage was less complete in these age groups. ${ }^{18}$ The SNC was approved by the Cantonal Ethics Committees of Bern and Zurich.

\section{Identification of suicides}

From 2000 onwards three right-to-die associations were assisting suicides in Swiss residents: Exit Deutsche Schweiz, Exit Romandie and Dignitas. ${ }^{7,9,19}$ The three associations provided anonymous data on all suicides of Swiss residents they assisted between 2003 and 2008 to the FSO. We identified these deaths in the SNC based on the date of birth, date of death, gender, place of residence and underlying diseases mentioned on the death certificate, based on a legal agreement with the FSO. ${ }^{12}$ Unassisted suicides were 
identified based on ICD- $10^{20}$ codes for deaths caused by self-harm (X60.0-X84.0). We classified these deaths as unassisted suicides unless they were identified as an assisted suicide by the right-todie associations.

\section{Underlying disease}

We determined the ICD-10 codes recorded on the death certificates. We used the first underlying cause listed and created categories of all-cancer (C00-C97), mental and behavioural disorders (F00-F99), diseases of the nervous system (G00-G99), diseases of the circulatory system (I00-I99), diseases of the musculoskeletal system (M00-M99) and other diseases (A00-B99, D00-D89, E00-E90, H00-H95, J00-J99, K00-K93, L00-L99, N00-N99,O00-O99, P00-P96, Q00-Q99, R00-R99). Separate analyses were done for cancers of the digestive system (C15-C26), cancers of the respiratory system (C30-C39), breast cancer (C50), cancers of male genital organs (C60-C63) and other cancers as well as for mood disorders (F30-39) and other mental diseases. Motor neuron diseases such as amyotrophic lateral sclerosis (G12.2), Parkinson's disease (G20), multiple sclerosis (G35) and other nervous system disease were also analysed separately.

\section{Statistical analysis}

We calculated crude rates of unassisted and assisted suicide by dividing the number of suicides by the number of person-years at risk and estimated hazard ratios using Cox regression. Time of observation started on 1 January 2003 and ended on the earliest of the date of death, emigration or on 31 December 2008. The models included gender, age, religion (Protestants, Catholics and no affiliation), education (compulsory schooling, secondary and tertiary education), marital status (single, married, divorced and widowed), type of household (single person, multiple and institution), children (yes or no), urbanisation (urban, peri-urban and rural), the Swiss neighbourhood index of socioeconomic position (Swiss SEP, in four quartiles), language region (German, French and Italian) and nationality (Swiss or foreign). The Swiss SEP is based on 1.3 million overlapping neighbourhoods of about 50 households and data from the 2000 census on the median rent per square metre, the mean number of people per room and the proportions of households headed by someone with primary education or less, and headed by a person in a manual or unskilled occupation. ${ }^{21}$

We determined the percentage of unassisted and assisted suicides with different underlying causes recorded on the death certificate. Finally, for deaths with an underlying cause of cancer or diseases of the nervous system and circulatory or musculoskeletal system disorders we did a logistic regression analysis to examine gender differences in the probability of suicide, unassisted suicide and assisted suicide. These conditions are common among people who die by assisted suicide in Switzerland. ${ }^{12}$ Logistic models were adjusted for age, religion, education, marital status, type of household, urbanisation, neighbourhood socioeconomic position, language region, nationality and the underlying disease reported on the death certificate. Statistical analyses were done using Stata version 12. Results are given as rates per 100000 person-years, hazard ratios (HRs), odds ratios (ORs) and percentages of assisted suicides across different underlying diseases, with $95 \%$ confidence intervals.

\section{Results}

\section{Study population}

The SNC included 7275402 individuals at the end of 2000. A total of $189980(2.6 \%)$ people were excluded from the current analyses because they died or emigrated between the 2000 census and 1 January 2003. Furthermore, 2076910 (28.5\%) individuals younger than 25 years at census and $4109(0.6 \%)$ individuals aged 95 years or older were excluded. Therefore 5004403 people were included in the analyses. In total 357879 individuals died during the study period.

The three right-to-die associations reported 1325 assisted suicides in individuals aged 25-94 years at the census. In total, 24 assisted suicides (1.8\%) could not be identified in the SNC: 1301 assisted suicides were thus included in the analysis. In the SNC, 6950 deaths in individuals aged 25-94 years at the census were coded as suicides. Of the 1301 assisted suicides, 1242 (96\%) were coded as suicides and subtracted from the total number of suicides. A total of 5708 unassisted suicides were therefore included. Whereas the number of unassisted suicides fluctuated between 900 and 983 per year, the number of assisted suicides increased from 187 in 2003 to 246 in 2008.

The socioeconomic and demographic characteristics of the population at risk and of the individuals who died by assisted or unassisted suicides are shown in Table 1 (for a table detailing a larger number of characteristics see online Table DS1). The median age of the individuals that died with assistance was 72 years (interquartile range 60-79 years) compared with a median age of 50 years (interquartile range 40-64 years) for the individuals that died by unassisted suicide. Compared with unassisted suicide, those dying by assisted suicide were more likely to be women, to have no religious affiliation, to have tertiary education and to be widowed and living alone. Individuals dying by assisted suicide were also more likely to live in neighbourhoods of higher socioeconomic status and to live in urban areas than those dying by unassisted suicide.

\section{Rates of assisted and unassisted suicide}

Based on 28.7 million person-years of follow up, rates of unassisted and assisted suicide were 19.9 and 4.5 per 100000 (Table 1). Rates increased with age, with a steeper increase for assisted suicide (from 0.3 in age group 25-34 years to 38.9 in age group 85-94 years) than for unassisted (from 13.8 to 30.1). The rate of unassisted suicides in men was almost three times that of women (29.6 v 11.0), whereas rates of assisted suicides were more similar (4.1 in men, 5.0 in women). In both groups the rates were higher in people without a religious affiliation, and higher in Protestants than in Catholics, but the differences were larger in assisted than in unassisted suicides. Other patterns were similar in assisted and in unassisted suicides: rates were higher in widowed and divorced people compared with married people, and higher in Swiss citizens than in foreigners. Whereas people with secondary education had the highest rate of unassisted suicide, people with tertiary education had the highest rate of assisted suicide. The rates of assisted suicide, but not of unassisted suicides, increased with higher socioeconomic position of neighbourhoods. For both assisted and unassisted suicides, there were interactions between age and gender $(P<0.001)$ and other variables. Further analyses were therefore stratified by age (25-64 years, 65-94 years) and gender. The cut-off at 65 years reflects retirement age for men in Switzerland.

\section{Multivariable analyses}

Figure 1 shows the results from multivariable Cox models stratified by gender and age group and adjusted for age, degree of urbanisation, socioeconomic status of neighbourhood, language region and nationality. The HRs shown in the figure are given in online Tables DS2-DS5. The association with religious 


\begin{tabular}{|c|c|c|c|c|c|}
\hline & \multirow{2}{*}{$\begin{array}{l}\text { Study population } \\
n(\%)\end{array}$} & \multicolumn{2}{|c|}{ Unassisted suicides } & \multicolumn{2}{|c|}{ Assisted suicides } \\
\hline & & $n(\%)$ & Rate per 100000 & $n(\%)$ & Rate per 100000 \\
\hline Total & $5004403(100)$ & $5708(100)$ & 19.9 & $1301(100)$ & 4.5 \\
\hline \multicolumn{6}{|l|}{ Gender } \\
\hline Male & $2402899(48.0)$ & 4068 (71.3) & 29.6 & 561 (43.1) & 4.1 \\
\hline Female & $2601504(52.0)$ & $1640(28.7)$ & 11.0 & $740(56.9)$ & 5.0 \\
\hline \multicolumn{6}{|l|}{ Age, years } \\
\hline $25-34$ & $1061090(20.9)$ & 869 (15.2) & 13.8 & $18(1.4)$ & 0.3 \\
\hline $35-44$ & 1177743 (23.1) & $1301(22.8)$ & 18.7 & $50(3.8)$ & 0.7 \\
\hline $45-54$ & $986903(19.4)$ & $1268(22.2)$ & 21.8 & $143(11.0)$ & 2.5 \\
\hline $55-64$ & 775352 (15.3) & $909(15.9)$ & 20.2 & 228 (17.5) & 5.1 \\
\hline $65-74$ & 564545 (11.4) & 739 (13.0) & 23.4 & $360(27.7)$ & 11.4 \\
\hline $75-84$ & $341317(7.4)$ & $520(9.1)$ & 31.3 & 370 (28.4) & 22.3 \\
\hline $85-94$ & $97453(2.6)$ & $102(1.8)$ & 30.1 & $132(10.2)$ & 38.9 \\
\hline \multicolumn{6}{|l|}{ Religion } \\
\hline Protestant & 1813645 (36.2) & $2312(40.5)$ & 22.3 & $612(47.0)$ & 5.9 \\
\hline Catholic & 2114883 (42.3) & 2087 (36.6) & 17.2 & $272(20.9)$ & 2.2 \\
\hline No affiliation & 578718 (11.6) & 930 (16.3) & 27.7 & 331 (25.4) & 9.9 \\
\hline Other/unknown & $497207(9.9)$ & $379(6.6)$ & 13.3 & $86(6.6)$ & 3.0 \\
\hline \multicolumn{6}{|l|}{ Education } \\
\hline Compulsory & 1157143 (23.1) & $1182(20.7)$ & 18.5 & $270(20.8)$ & 4.2 \\
\hline Secondary & 2600564 (52.0) & $3211(56.3)$ & 21.3 & $687(52.8)$ & 4.6 \\
\hline Tertiary & 1095834 (21.9) & $1196(21.0)$ & 18.7 & 335 (25.7) & 5.2 \\
\hline Unknown & $150826(3.0)$ & $119(2.1)$ & 13.7 & $9(0.7)$ & 1.0 \\
\hline \multicolumn{6}{|l|}{ Marital status } \\
\hline Single & 975300 (19.5) & $1434(25.1)$ & 25.3 & $157(12.1)$ & 2.8 \\
\hline Married & 3268448 (65.3) & $3108(54.4)$ & 16.4 & $642(49.3)$ & 3.4 \\
\hline Widowed & $363677(7.3)$ & 416 (7.3) & 22.9 & $314(24.1)$ & 17.3 \\
\hline Divorced & 396978 (7.9) & 750 (13.1) & 32.7 & 188 (14.5) & 8.2 \\
\hline
\end{tabular}

affiliation was stronger in assisted than in unassisted suicides $(P<0.05$ for difference in all groups). Whereas higher education was associated with assisted suicide, primary education was a risk factor for unassisted suicide. The association with marital status was stronger in unassisted than in assisted suicides, whereas the association with having children was similar between assisted and unassisted suicide.

\section{Underlying diseases}

In 1091 (83.9\%) assisted and in 3007 (52.7\%) unassisted suicides the death certificates mentioned at least one underlying disease (online Tables DS6 and DS7). Among unassisted suicides mental disorders dominated both in men and women, but women were more likely to have a mental illness recorded than men: $51.5 \%$ v. $35.9 \%$ in the younger and $43.9 \%$ v. $26.6 \%$ in the older age group (Fig. 2). Conversely, men were more likely than women $(10.3 \%$ v. $8.8 \%$ in the younger and $20.9 \%$ v. $14.1 \%$ in the older age group) to have causes other than mental illnesses recorded on their death certificate, including cancers, nervous system and circulatory diseases. Among assisted suicides, cancer dominated, followed by diseases of the nervous system, circulatory and musculoskeletal diseases. Men were more likely to have a cancer recorded on the death certificate, whereas multiple sclerosis or musculoskeletal conditions were more common in women (Fig. 2).

Among the 205236 deaths with cancer, diseases of the nervous, circulatory and musculoskeletal systems as the underlying cause the adjusted odds of dying by suicide overall was similar for women and men in the younger age group, whereas it was slightly lower in women in the older age group (Table 2). The adjusted odds of dying by assisted suicide was, however, higher among women than men in both age groups, whereas women were much less likely than men to die by unassisted suicide. Online Tables DS8 and DS9 show the complete results of the logistic regression model, stratified by age group.

\section{Discussion}

\section{Main findings}

In Switzerland, sociodemographic factors associated with assisted and unassisted suicide differed in magnitude, and sometimes in direction. For example, whereas individuals with tertiary education had a lower risk of unassisted suicide compared with people with primary education, they were more likely to die by assisted suicide. Suicide rates were higher in people without religious affiliation than in Catholics or Protestants, but the association was considerably stronger for assisted suicide than unassisted suicide. Divorced people and those living alone had a higher rate of unassisted and assisted suicide. Mental and behavioural disorders were the most common underlying causes recorded on the death certificate of unassisted suicides, whereas cancer was the most common condition among those who died by assisted suicide. Interestingly, when restricting analyses to deaths with underlying causes typically associated with assisted suicide, ${ }^{12}$ the suicides in men tended to be unassisted whereas those in women were more frequently assisted suicides.

\section{Strengths and limitations}

To our knowledge this is the first study comprehensively comparing sociodemographic factors associated with assisted and unassisted suicide. Switzerland is one of few countries worldwide $^{7}$ where assisted suicide is legal. The right-to-die 
(a)

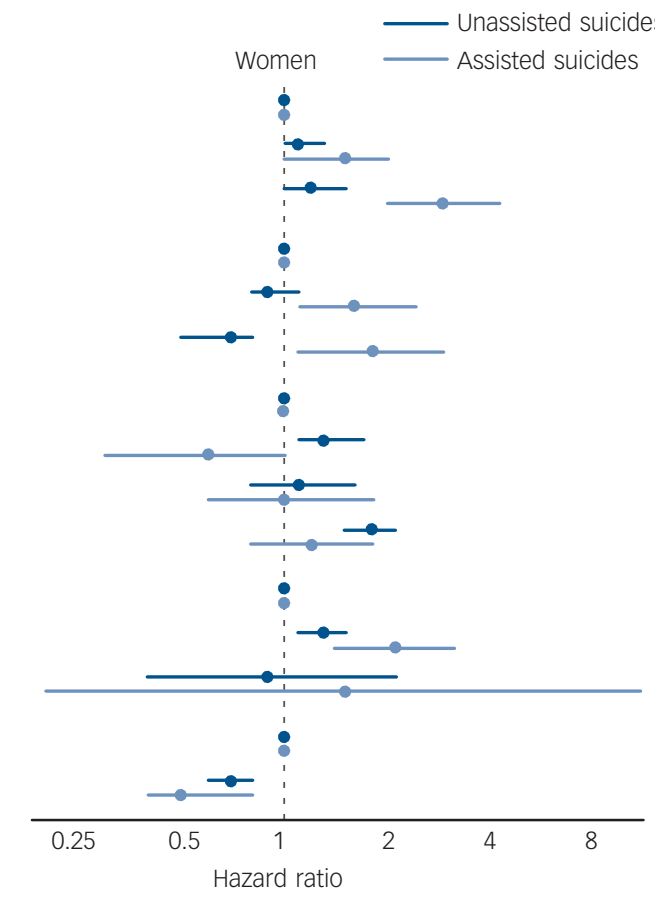

(b)
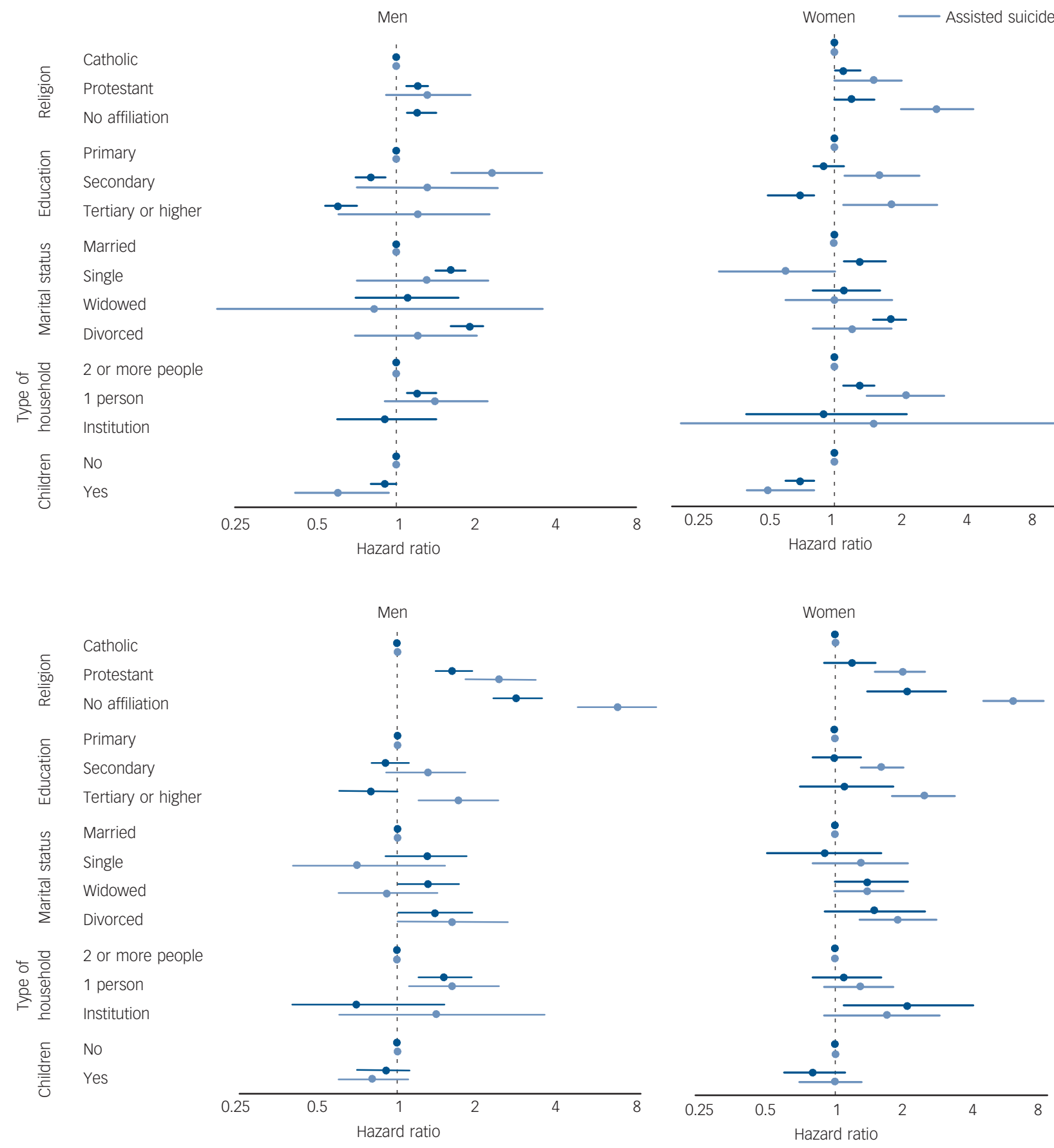

Fig. 1 Hazard ratios and 95\% confidence intervals for unassisted and assisted suicides from multivariable Cox models by age at census and gender.

(a) 25-64 years; (b) 65-94 years. Models adjusted for age, urbanity, socioeconomic index of the neighbourhood, language region and nationality.

associations provided anonymous data on all suicides they assisted during the study period, which allowed us to examine assisted suicides in the SNC. The SNC is a longitudinal mortality study of the entire Swiss population that was created by linking census with mortality records, with data at the level of the individual, household and building. ${ }^{15}$ However, our study also has several limitations. Mental disorders such as psychoses or depression are the dominant risk factors for unassisted suicide, ${ }^{3}$ however, we only had access to diagnoses reported on the death certificate and no information on mental and behavioural disorders diagnosed before death. For example, it is unclear whether women dying by unassisted suicide had more mental health problems than men, whether women were diagnosed more often, or whether psychiatric diagnoses were simply reported more comprehensively on their death certificates. Studies in which psychological autopsies were conducted estimated that about $90 \%$ of people who died by suicide had psychiatric disorders. ${ }^{3,22}$ Women are diagnosed with depression more often than men, who often show different symptoms. ${ }^{23,24}$ There are no studies on the reliability of the comorbidities reported on death certificates of people who died by suicide in Switzerland. In the USA slightly more psychiatric diagnoses are mentioned on death certificates of 
(a)

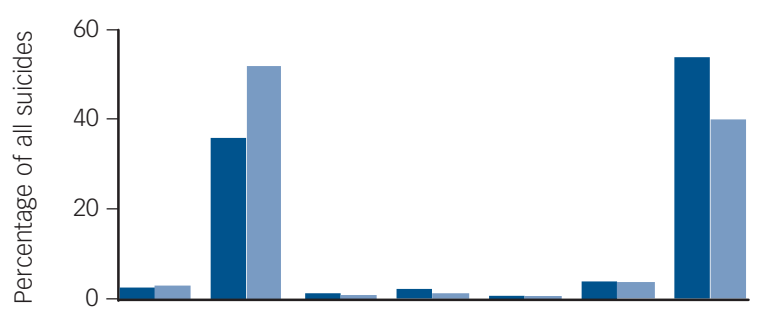

(b)

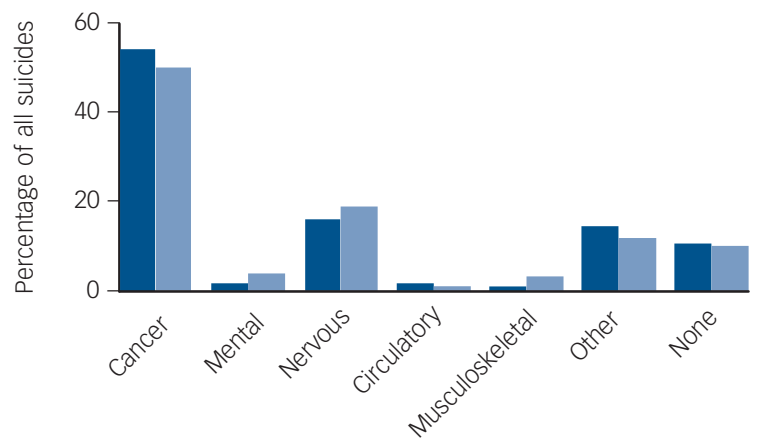

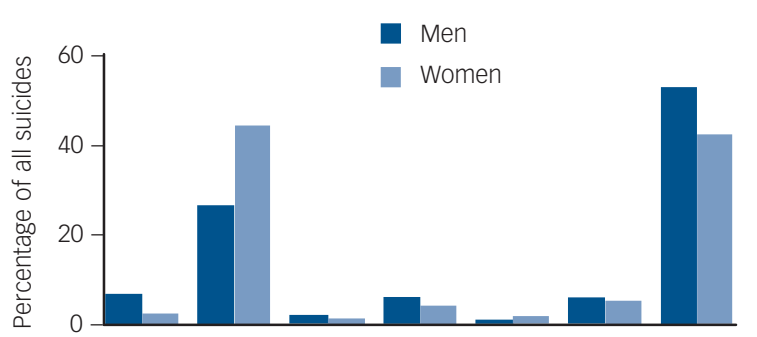

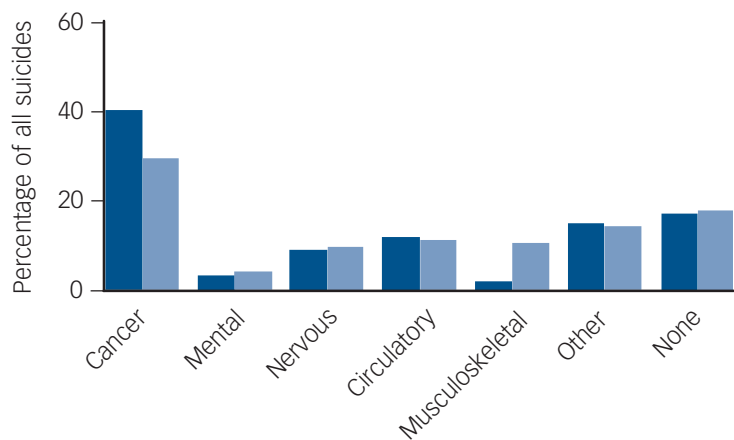

Fig. 2 Percentages of suicides in people with cancer, mental and behavioural disorders, nervous, circulatory or musculoskeletal system disorders, other diseases or no diseases recorded as underlying causes among those who died by (a) unassisted and (b) assisted suicide, by age group (younger age group (25-64 years) shown on the left, older age group (65-94 years) shown on the right) and gender.

women than of men, ${ }^{25}$ but not in Australia. ${ }^{26}$ Unfortunately, there is no registry for assisted suicide in Switzerland: we could therefore only include the suicides assisted by lay volunteers working for three right-to-die associations but not those assisted by private physicians. In a survey, $6 \%$ of doctors indicated that they had ever assisted a suicide without involvement of a rightto-die association. ${ }^{27}$ It is not known how large the group of these patients is in comparison to those who died assisted by an organisation and whether the sociodemographic factors and comorbidities are different between these two groups. As the SNC relies on routine mortality records, some suicides might have been misclassified as deaths because of other causes. ${ }^{28}$ Differential misclassification is unlikely in Switzerland because the family and the communal authorities do not receive a copy of the death certificate, and death registration is anonymous. Finally, the routine mortality data do not include information on the stage and the severity of the disease, and we had no data on the reasons why people chose to die by assisted or unassisted suicide, and what role underlying diseases played in their decision. ${ }^{29}$ In an earlier study conducted in Switzerland, prescribing physicians and patients most often mentioned pain and need for long-term care as reasons to ask for assistance in suicide. ${ }^{30}$ For patients the wish for autonomy was a further important reason. ${ }^{30}$

\section{Comparison with other studies}

Associations between socioeconomic factors and suicide have been documented in Western Europe, but the pattern and the magnitude vary between countries. ${ }^{31}$ In univariate analyses we found associations with both educational attainment and the socioeconomic position of neighbourhoods of residence but in the multivariable model only individual-level education remained. A previous study found an important association with individuallevel socioeconomic conditions in several countries. ${ }^{31}$ Both unassisted and assisted suicides were associated with living alone and having no children, again confirming the results of earlier studies. ${ }^{5,32}$ These associations support the notion that lack of social support is a risk factor for suicide. ${ }^{33}$ The stronger protective association of the Catholic religion with assisted than unassisted suicide is in line with previous results from the SNC. ${ }^{34}$

In accordance with a large body of literature we found that rates of suicide were higher in men than in women. ${ }^{35}$ Conversely, women have been shown to have higher rates of suicidal ideation and behaviours than men in most Western countries. ${ }^{35}$ In our study women were more likely to die by assisted suicide. This result is congruent with earlier studies on people who have died by assisted suicide in Switzerland. ${ }^{10,11}$ When restricting our analysis to deaths with underlying causes that are associated with

\begin{tabular}{|c|c|c|c|c|c|c|}
\hline \multirow[b]{2}{*}{ Age group } & \multicolumn{2}{|c|}{ All suicides } & \multicolumn{2}{|c|}{ Assisted } & \multicolumn{2}{|c|}{ Unassisted } \\
\hline & $n(\%)$ & OR (95\% Cl) & $n(\%)$ & OR (95\% Cl) & $n(\%)$ & OR (95\% Cl) \\
\hline 25-64 years old & $519(100)$ & & $292(100)$ & & $227(100)$ & \\
\hline Men & $300(57.8)$ & 1.00 & $126(43.2)$ & 1.00 & $174(76.7)$ & 1.00 \\
\hline Women & $219(42.2)$ & $1.06(0.84-1.22)$ & $166(56.8)$ & $1.8(1.37-2.25)$ & $53(23.3)$ & $0.42(0.30-0.58)$ \\
\hline $65-94$ years old & $721(100)$ & & $474(100)$ & & $247(100)$ & \\
\hline Men & $413(57.3)$ & 1.00 & $208(43.9)$ & 1.00 & 205 (83.0) & 1.00 \\
\hline Women & $308(42.7)$ & $0.81(0.68-0.96)$ & $266(56.1)$ & $1.5(1.20-1.90)$ & $42(17.0)$ & $0.18(0.12-0.26)$ \\
\hline
\end{tabular}


assisted suicide, ${ }^{12}$ the difference in the rate of suicide between women and men disappeared among those aged 25-64 years, and was substantially reduced in the age group 65-94 years. It is possible that among the terminally ill and those suffering unbearably, the prevalence of suicidal intentions is similar in women and men, but women are more likely to choose assisted suicide than men.

\section{Implications for policy and future research}

The increase in assisted suicides in recent decades has changed the epidemiology of suicide in Switzerland and analyses that distinguish between assisted and unassisted suicide are required to inform preventative interventions and policy. Further research is needed to examine to what extent palliative care and social support can prevent suicides in the terminally ill. Studies are also needed to measure and better understand the psychological distress caused by assisted and unassisted suicides of loved ones among relatives, friends and partners. A recent qualitative study found that most relatives of people who died by assisted suicide in Southern Switzerland felt that assisted suicide is preferable to unassisted suicide. ${ }^{36}$ Relatives who were actively involved in the decision process reported less emotional distress than relatives not involved in the process. Finally, further research is needed to clarify why men with a severe disease tend to choose unassisted suicide whereas women and those with more education more often choose assisted suicide. That higher education was positively associated with assisted suicide, but negatively with unassisted suicide may reflect differences in willingness for and access to assisted suicide. ${ }^{12}$ A legal obligation to report any assisted suicide to a central registry would allow monitoring of not only suicides assisted by right-to-die organisations, but also of suicides assisted by their physician. This would allow the investigation of differences in practices and in the factors associated with people dying with assistance and to detect problematic situations in which assisted suicides occur in Switzerland.

In conclusion, this comparative study of assisted and unassisted suicide in Switzerland found that sociodemographic factors that might indicate lack of social support and greater vulnerability were associated both with unassisted suicides and assisted suicides, whereas associations with other factors, such as gender or education differed between assisted and unassisted suicide.

Nicole Steck, PhD, Matthias Egger, MD, MSc, Marcel Zwahlen, PhD, Institute

of Social and Preventive Medicine, University of Bern, Bern, Switzerland

Correspondence: Marcel Zwahlen, Institute of Social and Preventive Medicine University of Bern, Switzerland. Email: marcel.zwahlen@ispm.unibe.ch

First received 13 Nov 2014, final revision 27 Feb 2015, accepted 16 Apr 2015

\section{Funding}

This work was supported by the Swiss National Science Foundation (grant nos. 3347CO108806, 33CS30_134273, 33CS30_148415 and 133139).

\section{Acknowledgements}

We thank the Federal Statistical Office (FSO) for providing mortality and census data and for the support that made the Swiss National Cohort and this study possible. We would like to especially thank Christoph Junker and Chantal Violand from the FSO for their help with this study. The members of the Swiss National Cohort Study Group are Matthias Egger (Chairman of the Executive Board), Adrian Spoerri and Marcel Zwahlen (Bern, Switzerland); Milo Puhan (Chairman of the Scientific Board), Matthias Bopp (Zurich, Switzerland); Nino Milo Puhan (Chairman of the Scientific Board), Matthias Bopp (Zurich, Switzerland); Nino
Künzli (Basel, switzerland); Fred Paccaud (Lausanne, Switzerland); and Michel Oris (Geneva, Switzerland).

\section{References}

1 World Health Organization. Suicide Prevention. WHO, 2014 (http:// www.who.int/mental_health/prevention/en/).

2 BFS. Todesursachenstatistik: sterblichkeit und deren hauptursachen in der schweiz [Swiss Statistics. Death and its main causes in Switzerland]. BFS Aktuell 2013; 1-4.

3 Cavanagh JT, Carson AJ, Sharpe M, Lawrie SM. Psychological autopsy studies of suicide: a systematic review. Psychol Med 2003; 33: 395-405.

4 Spoerri A, Zwahlen M, Bopp M, Gutzwiller F, Egger M. Religion and assisted and non-assisted suicide in Switzerland: National Cohort Study. Int J Epidemiol 2010; 39: 1486-94.

5 Schneider B, Lukaschek K, Baumert J, Meisinger C, Erazo N, Ladwig KH. Living alone, obesity, and smoking increase risk for suicide independently of depressive mood findings from the population-based MONICA/KORA Augsburg cohort study. J Affect Disord 2014; 152-154: 416-21.

6 Yeh JY, Xirasagar S, Liu TC, Li CY, Lin HC. Does marital status predict the odds of suicidal death in Taiwan? A seven-year population-based study. Suicide Life Threat Behav 2008; 38: 302-10.

7 Steck N, Egger M, Maessen M, Reisch T, Zwahlen M. Euthanasia and assisted suicide in selected European countries and US States: systematic literature review. Med Care 2013; 51: 938-44.

8 Burkhardt S, La Harpe R. Debates about assisted suicide in Switzerland. Am J Forensic Med Pathol 2012; 33: 410-3.

9 Andorno R. Nonphysician-assisted suicide in Switzerland. Camb Q Healthc Ethics 2013; 22: 246-53.

10 Bosshard G, Ulrich E, Bar W. 748 cases of suicide assisted by a Swiss right-to-die organisation. Swiss Med Wkly 2003; 133: 310-7.

11 Fischer S, Huber CA, Imhof L, Mahrer IR, Furter M, Ziegler SJ, et al. Suicide assisted by two Swiss right-to-die organisations. I Med Ethics 2008; 34: 810-4.

12 Steck N, Junker C, Maessen M, Reisch T, Zwahlen M, Egger M, et al. Suicide assisted by right-to-die associations: a population based cohort study. Int J Epidemiol 2014; 43: 614-22.

13 Hendin H. Suicide, assisted suicide, and medical illness. Harv Ment Health Lett 2000; 16: 4-7.

14 van Wijngaarden E, Leget $C$, Goossensen $A$. Experiences and motivations underlying wishes to die in older people who are tired of living: a research area in its infancy. Omega 2014; 69: 191-216.

15 Bopp M, Spoerri A, Zwahlen M, Gutzwiller F, Paccaud F, Braun-Fahrlander C, et al. Cohort profile: the Swiss National Cohort - a longitudinal study of 6.8 million people. Int J Epidemiol 2009; 38: 379-84.

16 Spoerri A, Zwahlen M, Egger M, Bopp M. The Swiss National Cohort: a unique database for national and international researchers. Int J Public Health 2010; 55: 239-42.

17 Renaud A. Methodology Report - Coverage Estimation for the Swiss Population Census 2000. Swiss Federal Statistical Office, 2004.

18 Schmidlin K, Clough-Gorr KM, Spoerri A, Egger M, Zwahlen M. Impact of unlinked deaths and coding changes on mortality trends in the Swiss National Cohort. BMC Med Inform Decis Mak 2013; 13: 1.

19 Hurst SA, Mauron A. Assisted suicide and euthanasia in Switzerland: allowing a role for non-physicians. BMJ 2003; 326: 271-3.

20 World Health Organization. The ICD-10 Classification of Mental and Behavioural Disorders: Clinical Descriptions and Diagnostic Guidelines. WHO, 1992.

21 Panczak R, Galobardes B, Voorpostel M, Spoerri A, Zwahlen M, Egger M. A Swiss neighbourhood index of socioeconomic position: development and association with mortality. J Epidemiol Community Health 2012; 66: 1129-36.

22 Hawton K, van Heeringen K. Suicide. Lancet 2009; 373: 1372-81.

23 Gutierrez-Lobos $K$, Scherer $M$, Anderer $P$, Katschnig $H$. The influence of age on the female/male ratio of treated incidence rates in depression. BMC Psychiatry 2002; 2: 3.

24 Akhtar-Danesh N, Landeen J. Relation between depression and sociodemographic factors. Int J Ment Health Syst 2007; 1: 4.

25 Rockett IR, Wang S, Lian Y, Stack S. Suicide-associated comorbidity among US males and females: a multiple cause-of-death analysis. Inj Prev 2007; 13 311-5.

26 Ruzicka LT, Choi CY, Sadkowsky K. Medical disorders of suicides in Australia: analysis using a multiple-cause-of-death approach. Soc Sci Med 2005; 61: 333-41.

27 Burkhardt S, Wyss K, La Harpe R. Assisted suicide in Switzerland: physicians' position [in French]. Rev Med Suisse 2007; 3: 2861-4. 
28 Tollefsen IM, Hem E, Ekeberg O. The reliability of suicide statistics: a systematic review. BMC Psychiatry 2012; 12: 9.

29 Guth U, Myrick ME, Reisch T, Bosshard G, Schmid SM. Suicide in breast cancer patients: an individual-centered approach provides insight beyond epidemiology. Acta Oncol 2011; 50: 1037-44.

30 Fischer S, Huber CA, Furter M, Imhof L, Mahrer IR, Schwarzenegger C, et al. Reasons why people in Switzerland seek assisted suicide: the view of patients and physicians. Swiss Med Wkly 2009; 139: 333-8.

31 Lorant V, Kunst AE, Huisman M, Costa G, Mackenbach J. Socio-economic inequalities in suicide: a European comparative study. Br J Psychiatry 2005; 187: 49-54.

32 Stravynski A, Boyer R. Loneliness in relation to suicide ideation and parasuicide: a population-wide study. Suicide Life Threat Behav 2001; 31 32-40.
33 Guo Q, Jacelon CS. An integrative review of dignity in end-of-life care. Palliat Med 2014; 28: 931-40.

34 Panczak R, Spoerri A, Zwahlen M, Bopp M, Gutzwiller F, Egger M. Religion and suicide in patients with mental illness or cancer. Suicide Life Threat Behav 2013; 43: 213-22.

35 Canetto SS, Sakinofsky I. The gender paradox in suicide. Suicide Life Threat Behav 1998; 28: 1-23.

36 Gamondi C, Pott M, Forbes K, Payne S. Exploring the experiences of bereaved families involved in assisted suicide in Southern Switzerland: a qualitative study. BMJ Support Palliat Care 2015; 5: 146-52.

\section{Lovely young consultant charms my husband}

\section{poems by doctors}

\section{Kate Compston}

'Look! here and here,' she breathes. I note

her intentness, as the three

of us pore over her strange map.

I see his greying face

light at her nearness, how he floats in her interest in him. I could be

half in love with her myself, lap

at her kindness greedily, but brace

myself to hear her verdict. Poet

in an alien tongue and territory, she

rhapsodizes about gaps

where gaps ought not to be. 'We trace

low dopamine uptake....' (she strokes her throat,

addressing me): 'Dementia - DLB.

Given the other signs - the overlap

of dream and real, the slowing pace,

visual hallucinations, remote

expression - this scan wraps

up my diagnosis ...'

(stops and holds his hand, devotes

herself to him): 'Together, we

will deal with this thing, yes?

Embraced

by her concern, he throws aside

encroaching night, flings his windows wide.

The trap door of my heart slams shut.

From The Hippocrates Prize 2015: The Winning and Commended Poems, selected by T Dalrymple, R Gross, F Oyebode and S Rae, eds MW Hulse \& DRJ Singer. The Hippocrates Press, 2015. (c) Kate Compston. Reprinted with permission. Kate worked in the NHS as a BACP Senior Counsellor and is now retired. 